\title{
Fassbinder's formula. A revolution depicted is a real one aborted.
}

\author{
Camille Akmut
}

\begin{abstract}
Fassbinder's principle of not showing successful revolutions on screen in order to incite real ones, is established. Internal examples from his own oeuvre are referenced : Fox and his Friends (1975) and The Third Generation in particular are discussed. External examples follow as part of a comparative analysis. [The, contemporaneously transparent, background for this article is The Matrix 4's release.]
\end{abstract}




\section{Introduction}

A first section establishes what we call "Fassbinder's Formula". I.e. Fassbinder's avoidance of successful or proper resistance attempts in his work.

We reference in this context a conference where the Director spoke about Fox and his Friends's background, giving broader insights into his philosophy (Fassbinder 1975b). A half-a-dozen other works spanning the years 1972 to 1979 are also evoked.

Brecht is briefly considered as precedent, as a prominent example of an artist known for their rebuttal of audience's pleasures - for political purposes.

A second section is dedicated to the discussion of how that formula relates to other significant, external works : accordingly, these are interpreted from the perspective of revolts shown and withheld.

\section{Fassbinder's formula}

"Fox and his Friends", as this film is known to English-speaking audiences, is a title already full of irony : Fox, of course has no friends, the movie makes amply clear while drawing closer to its hellish, infernal, inescapable ending.

Fox who falls deeply in love multiple times finds love nowhere : neither with partners, current or former, nor with relatives, nor with various other colorful and almost-always dubious associates :

In typical Fassbinder fashion, these range from overbearing family members (see virtually any of his output : Eff, 4 Jahreszeiten, Martha, 13 Moons....), bitchy gay bar audiences who thrive on rumors and misery, but also regularly attempt to issue warnings (fulfilling a role similar to that of oracles), morally flexible antique sellers, Moroccan straight-for-hire well hung prostitutes etc. etc..

And, certainly, Fox finds no satisfaction in material things : an expensive red sports car barely lasts a day.

One aspect of this minor, greatly underestimated work is that its real ending was never shown or shot - as Fassbinder discussed in a conference $^{1}$;

The film crew - already subjected to an abundance of penises, and the lowest of human behaviors - finally mutinied when asked to film Fox's corpse naked.

${ }^{1}$ ibid (about 5:30) 
In that same conference, the Director discussed his principle - called "Fassbinder's formula" on the occasion of this article - of never showing (successful) revolutions.

Depicting an actual revolt had the risk of preventing a real one, while showing abject failures - produced by capitalism at an incalculable great rate - had the exact opposite effect.

The former meant the viewer was depleted of all energy and will, in the latter case they were made angry and dangerous enough to consider alternatives to working-voting-and-decrepitude.

" a worker [who watches Fox...], should be full of rage and get the feeling they need to do something. I'd rather have something like this, than the opposite, namely filming or showing a worker's liberation such that the [really-existing] worker now is filled with the feeling they don't need to do that for themselves anymore" (followed by applause)

And further, responding to recurrent discontent about the ending :

"I'm exactly of the opposite viewpoint. Actually, isn't it so that when one watches a film, whether it be this one or another, and bad things occur, one also wishes to defend themselves against those things in their own lives?

\section{I do not believe that when revolutions happen in movies, that that's revolutionary." [trans.]}

Based on a friend's story minus the ultimate outcome, he stated, the film told a story that illuminates "the things that necessarily need to happen between people that are forced to live in certain, given conditions, systems" [ibid, 0-8m.]

In The Third Generation, another of Fassbinder's films, that formula is applied in the most obvious way : a terrorist group - composed principally of middleto -upper class characters - disintegrates amid paranoia and actual betrayal, vaguely evocative of some of the dimensions of anarchism.

The end result being a baroque farce where cross-dressing terrorists meet State repression in a grand explosion. Meanwhile, a technology company is planning on turning a profit by selling hardware to meet the security demand generated by this climate.

Worse even, the revolution was doomed from the start : at least one of the members is revealed to have played multiple sides from the quasi beginning.

The collaborative movie-documentary Germany in Autumn revolves around the death of the RAF founders: including Fassbinder's mother's defense of "democracy", and asymmetric memorials.

Germany... is a type of film-a-clef where the artist's struggle to retain integrity in the capitalist system mirrors the revolutionary's own anxieties :

"- But, Sir, it's a play from the 5th c. (BC)!

- Even more so: It's bad enough to know that these terrorist broads/bitches already existed then..." 
Antigone defies the laws or decrees of her city. Documentary-style segments echo this play with extended discussions of whether terrorists should be buried at all, or like "normal people" quote, with various businesses refusing service.

On the outskirts of the city, in a wooden area -Dornhaldenfriedhof- they are buried. Students, mothers and their children as well as young couples attend. In contrast, Scheleyer gets the funeral of a king.

Hans M. Scheleyer, celebrated in death by a cross-over alliance of mainstream political forces, was a former Nazi turned business magnate in booming 1970s West-Germany (the backdrop of essentially all Fassbinder films). Until he was put in a trunk, one day.

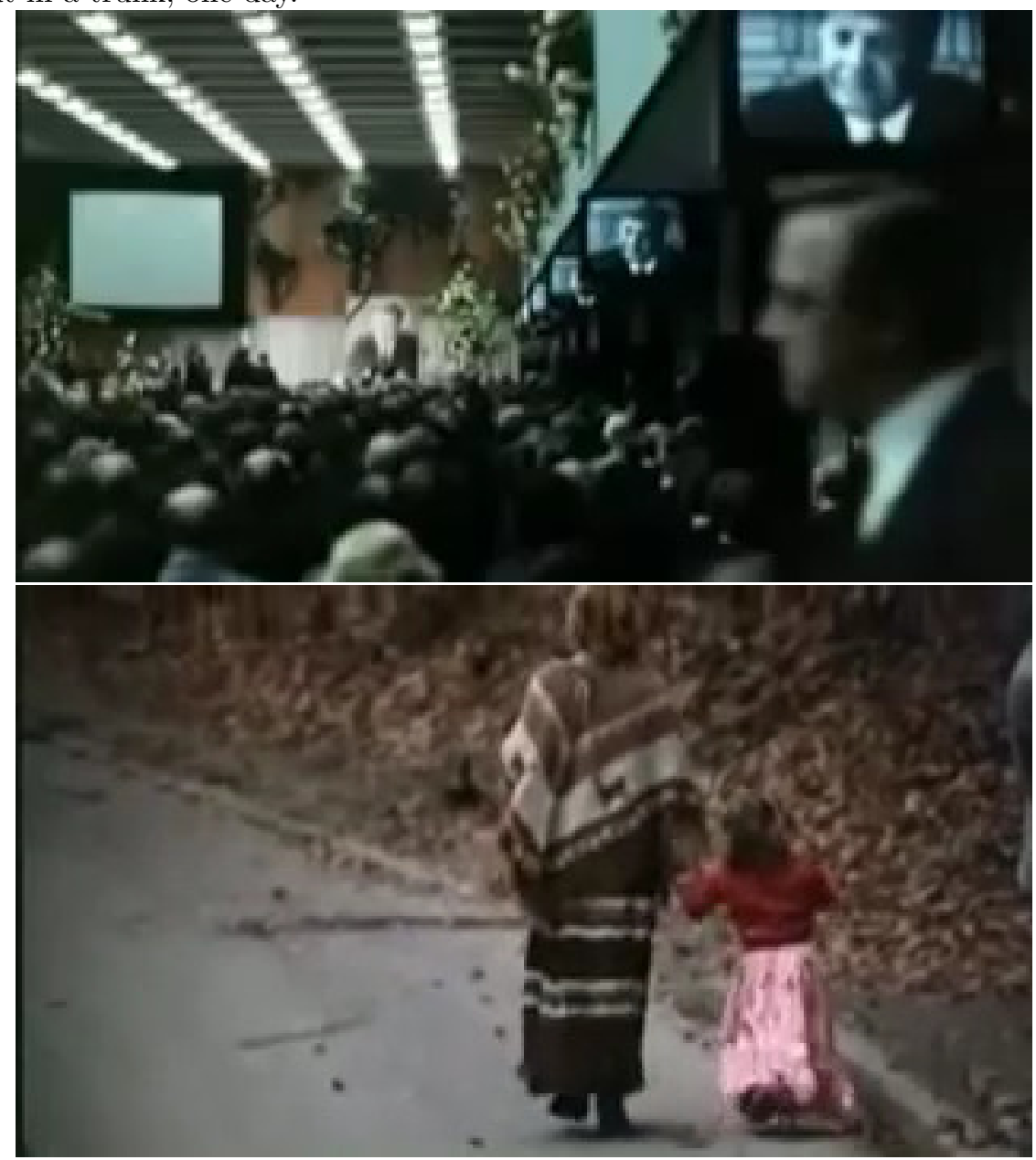

"The old Nazis were everywhere... in the justice-legal system, the administration, ministries, universities... President [Kanzler] Adenauer explained : "We need people who understand something about how things work the old way" 1

${ }^{1}$ Sueddeutsche nov 12. See now Alice Weidel : far right, lesbian, ex Goldman Sachs/tech... 
In this particularly striking segment of the film, a group of producers and a director discuss the potential funding of an adaptation of a famous Ancient Greek tragedy (transcript translated from memory, above) :

The problem with financing Antigone(?) would be that, if adapted too liberally for the modern public, it might be interpreted as a validation or approval of certain current political movements/events.

Fassbinder's own disapproval of State bodies in charge of financing the arts was a matter of public knowledge (see the same conference to which we refer) and this segment can be regarded as autobiographical in nature, uncontroversially.

And, while he did play Fox, obviously enjoying every minute of it ("finally, he could fulfill his fantasy of just being a simple kid from the underground!" noted a collaborator justly), he came from the very same social milieu as Fox's - elite, adroit - boyfriend.

The relationship with Brecht is obvious, who created an entire oeuvre out of denying (Bourgeois) theater goers their petty little pleasures, starting with their instinctive needs for catharsis derived from a nice, convenient, morally-square story.

Political goals seem to animate both artists : denial of immediate gratification should serve political goals (i.e. crafting an intelligent public, rather than a sentimental one).

In Fassbinder's work everyone dies, hence no one could be held responsible for spoilers :

Fox dies from an overdose, Martha survives beyond-horrific treatment by her husband but goes through an internal death as she gradually accepts her position, Effi dies from some psycho-somatic illness ('over-excitement'), people hang themselves in 13 Moons while Kant's philosophy is discussed, and on and on..

Fassbinder can be accused of many things, but not that he wasn't a committed artist. His refusal to depict resistance within the capitalist order as a long-lasting solution was consistent.

\section{Revolutions shown and withheld - in other works}

Brazil, a particularly intelligent film, has also the large drawback for the commentator that almost any interpretation is possible, and possibly encouraged.

The existence of two known endings, including one dubbed as "happy", further complicate this. 
Anti-communist, anti-capitalist, ecological, techno-critical, feminist interpretations are possible. Even interpreting Brazil as a romantic story cannot be totally excluded (the cottagecore ending), although it strikes as somewhat naive, and limiting.

Anti-communist readings might, for instance, emphasize the gigantic bureaucracy that defines the oppressive world in which Brazil takes place (we seem to remember, however, writings by two German ex-philosophers calling for the abolition of the State, in fact a main point of their political philosophy - as side note).

Anti-capitalists may in turn focus on Brazil taking place during the Christmas season (the most wasteful of all, all the while permeated by contradictory Christian teachings and tenets). Capitalism, there, has finally reached such an extreme state that terrorist counter-attacks have become part of the decor, and dinners and brunches in fancy and high places quickly resume.

"Such a lovely shade, such delicate nuances" a distinguished Madame exclaims, between two bites and bombs.

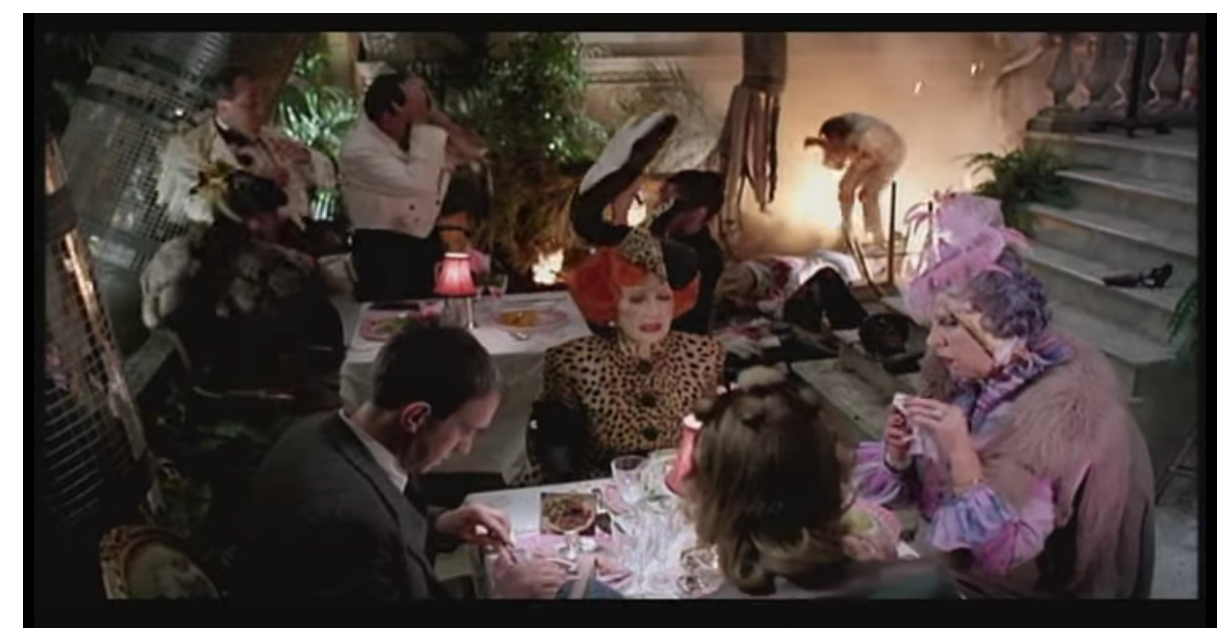

Among many other clever moments : a pin on one of the side-characters appears to hold "Consumers for Christ"(?), announcing all the absurdities of contemporary id. politics.

In any case, material for other views are not lacking : a world dominated by industries, where technology mostly only serves to crush people, with only a few hackers attempting to use them for liberation, and where high positions are occupied by men...

These various complications and layers of interpretations put Brazil in the same category as The Matrix : see the effervescence of various The philosophy of Matrix books.

Zizek, perhaps the most famous contemporary illustration of someone who can 
offer explanations for virtually anything, at his best would talk about 'unfreedoms', that is restrictions lived as complete liberties.

Brazil's ending, at a basic level, nonetheless seems to indicate that the attempted resistance failed - except, tragically, in the head of the protagonist submitted to torture...

Mr. Robot, a not quite as original work, follows the same end pattern ("maybe it was just a dream").

$99.9 \%$ of its content conforms nevertheless to the - opposite - model of a successful revolution unveiled, described in abundant detail.

Cryptocurrencies, (of all things), stolen from "the 1\% of the 1\%" are redistributed to the masses with grandiose talks of wealth redistribution happening in the background.

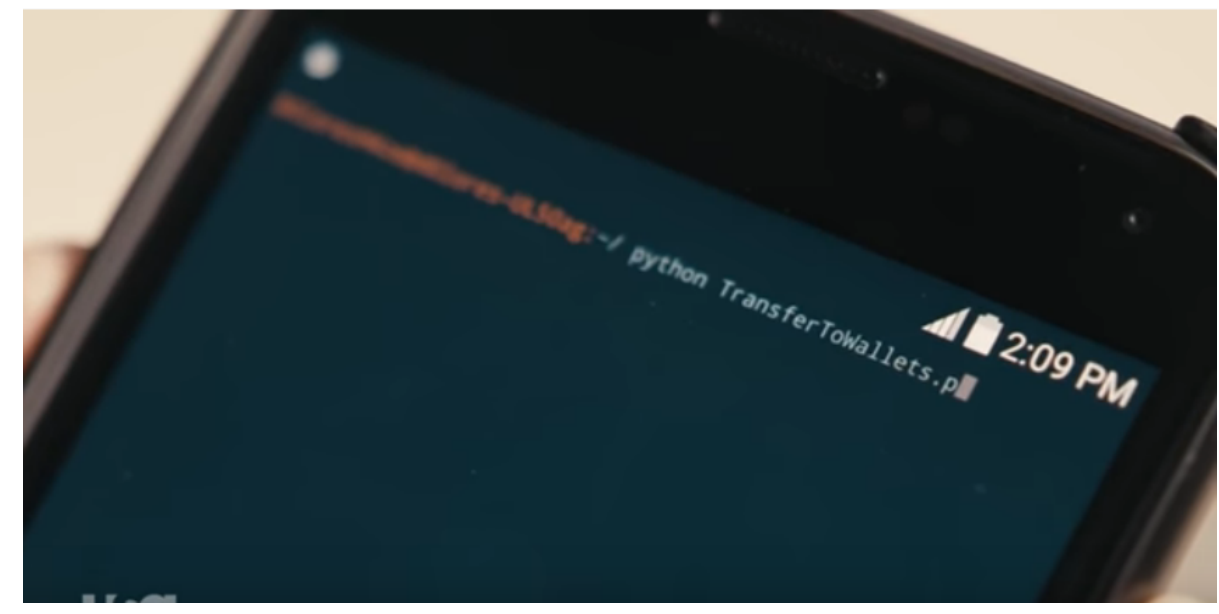

Viewers, after many seasons, countless episodes, and even more high-octane moments, can now breath again and go back to their normal lives, having thus witnessed a real revolution unfold on their screens, (perhaps Netflix);

Thus emptied from the responsibility of thinking deeply about their own lives.

For, how does one know when night is in an underground station... 
Ref.

- Fassbinder, Rainer. 1975. Faustrecht der Freiheit (Fox and his friends)

Fassbinder, Rainer. 1975b. Q\&A at the Austrian Film Museum.

"Woher wissen Sie das Nacht is' in einem Bahnhof?"

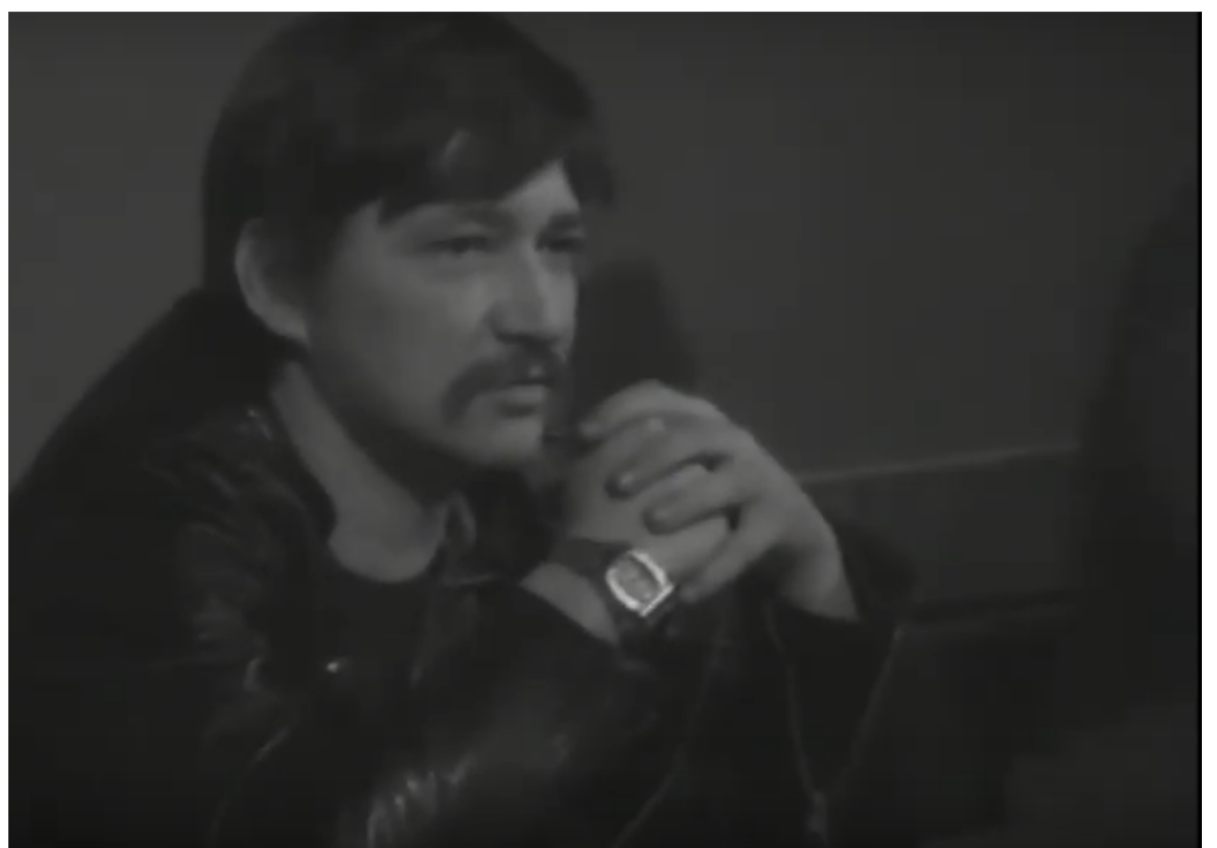

1972. Haendler der vier Jahreszeiten (The Merchant of Four Seasons).

- 1974. Effi Briest.

1974. Martha.

_ 1978. In a Year with 13 Moons.

1979. The Third Generation.

_ Gilliam, Terry. 1985. Brazil.

_ Brecht. Dreigroschenoper.

_ Mr. Robot. Season 4.

_ Fassbinder, Kluge, Schloendorff et al. 1978. Germany in Autumn. 


\begin{abstract}
Afterword
"I do not believe that revolutions happening in movies is revolutionary."

Fassbinder's work, object of many criticisms, could thus be summarized as 'anti revolutionary'-truly revolutionary art (in that complex sense).

In 36 long years, Fassbinder created an oeuvre that melted reality and fiction, personal life and the artistic and professional one, to such degrees that his own life could only end up resembling his screenplays.

Homophobe, misogynist, and probably racist too, he had won all the awards of normal society.

Untimely, he had become a bothersome figure in an economically successful, yet highly divided society that could never deal with itself.

Hence the many efforts spent on refashioning that past until it fit. while destroying the memory of those who opposed it..
\end{abstract}

